\section{Improving recognition of spondyloarthropathy in primary care: an unmet need}

Thank you for the opportunity to respond to Maxwell et al's letter and their insightful comments regarding the delay to diagnosis in axial spondyloarthritis (axSpA). In their audit of patients with coexisting chronic back pain and acute anterior uveitis (AAU), it was noted that such patients are poorly evaluated for suspected $\mathrm{SpA}$ at primary-care level. ${ }^{1}$

Poor recognition and consequent late referral remains a major stumbling block towards 'overall success' in axSpA. In our Dublin Uveitis Evaluation Tool (DUET) study, we also found that $62 \%$ of patients with undiagnosed SpA had previously consulted either their general practitioner (GP) or other allied health professionals with their backache but the diagnosis of SpA was not considered. ${ }^{2}$ The gatekeeper role of the GP cannot be underappreciated. However, variations in GP referral rates exist; indeed a 20-fold variation in GP referral rate has been reported. ${ }^{3}$ Clearly, the focus should be on efforts to increase the number of appropriate referrals, regardless of the referral rate. One approach is to promote the understanding and diagnostic skills of GPs in relation to axSpA and to develop specific diagnostic algorithms both for those with AAU (DUET algorithm) and for those with inflammatory-type back pain without AAU. As a part of our DUET project, we have developed SpA educational material for patients, GPs and ophthalmologists, which include general information on SpA, extra-articular manifestations and comorbidities. We have also developed a patient handout to be given to patients with AAU not requiring current referral to a rheumatologist that aims to provide patients with information with regard to SpA symptoms should they arise. We have conducted rheumatology/ophthalmology advisory board meetings at national level to seek insights from ophthalmologists in relation to $\mathrm{SpA}$ and the usefulness of DUET algorithm in daily practice. This has facilitated and informed our future roll-out plans to community ophthalmologists and GPs. Given the strong association between AAU and axSpA, the use of DUET algorithm provides a unique opportunity given its very high sensitivity and specificity. Furthermore, the excellent performance of the DUET algorithm was achieved without including inflammatory back pain (IBP) in the referral pathway and this is an important strength of this algorithm.

Together with our primary-care colleagues, we need to focus now on the development, validation and implementation of a diagnostic algorithm to be used in primary care to identify patients with axSpA who present with inflammatory-type back pain but without AAU. Such algorithms have been proposed but have not been adequately validated or applied routinely in primary care. ${ }^{4}$ Inconsistencies in diagnosing IBP in primary care are well established, ${ }^{6}$ and recent developments regarding the diagnostic criteria for IBP and Ankylosing Spondylitis (AS) have not permeated sufficiently into primary care. Not surprisingly, the audit by Maxwell et al also confirmed that the appropriate questions regarding low-back pain are not being addressed.

In conclusion, the early diagnosis and treatment of SpA has consistently been shown to improve short-term and long-term outcomes, ${ }^{7-10}$ and thus it is imperative that efforts are made to expedite the diagnosis. Since a significant delayed diagnosis is common among patients with $\mathrm{SpA},{ }^{11}$ uveitis presents a unique opportunity for identifying such patients with undiagnosed
SpA, and studies clearly show that AAU may frequently be the first interaction with medical care. ${ }^{12} 13$

\section{Muhammad Haroon, ${ }^{1,2}$ Oliver FitzGerald ${ }^{3,4}$}

${ }^{1}$ Division of Rheumatology, Department of Medicine, University Hospital Kerry, Tralee, Ireland

${ }^{2}$ Clinical Senior Lecturer, University College Cork, Cork, Ireland

${ }^{3}$ Department of Rheumatology, St Vincent's University Hospital, Dublin, Ireland

${ }^{4}$ Conway Institute for Biomolecular Research, University College Dublin, Dublin, Ireland

Correspondence to Professor Oliver FitzGerald, Department of Rheumatology, St Vincent's University Hospital, Dublin 4, Ireland; oliver.fitzgerald@ucd.ie

Competing interests None declared.

Provenance and peer review Commissioned; internally peer reviewed.

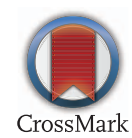

To cite Haroon M, FitzGerald O. Ann Rheum Dis 2016;75:e19.

Accepted 10 January 2016

Published Online First 28 January 2016

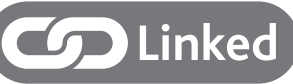

- http://dx.doi.org/10.1136/annrheumdis-2015-208983

Ann Rheum Dis 2016;75:e19. doi:10.1136/annrheumdis-2016-209118

\section{REFERENCES}

1 Maxwell $A$, Yates $M$, Everden $P$, et al. Does the co-existence of acute anterior uveitis and chronic back pain prompt primary care physicians to consider a diagnosis of axial spondyloarthritis? Ann Rheum Dis 2016;75:e18.

2 Haroon M, O'Rourke M, Ramasamy P, et al. A novel evidence-based detection of undiagnosed spondyloarthritis in patients presenting with acute anterior uveitis: the DUET (Dublin Uveitis Evaluation Tool). Ann Rheum Dis 2015;74:1990-5.

3 O'Donnell CA. Variation in GP referral rates: what can we learn from the literature? Fam Pract 2000;17:462-71.

4 Juanola Roura X, Collantes Estévez E, León Vázquez F, et al. Recommendations for the detection, study and referral of inflammatory low-back pain in primary care. Reumatol Clin 2015;11:90-8.

5 van Hoeven L, Luime J, Han $\mathrm{H}$, et al. Identifying axial spondyloarthritis in Dutch primary care patients, ages $20-45$ years, with chronic low back pain. Arthritis Care Res (Hoboken) 2014;66:446-53.

6 Jois RN, Macgregor AJ, Gaffney K. Recognition of inflammatory back pain and ankylosing spondylitis in primary care. Rheumatology (Oxford) 2008;47:1364-6.

7 Rudwaleit M, Schwarzlose S, Hilgert ES, et al. MRI in predicting a major clinical response to antitumour necrosis factor treatment in ankylosing spondylitis. Ann Rheum Dis 2008:67:1276-81.

8 Giardina A, Ciccia F, Principato A, et al. Patients with short duration (5 years) ankylosing spondylitis respond rapidly and maintain partial remission over a two years period when treated with TNF-blocking agents. Ann Rheum Dis 2008;67624 (Suppl II):624.

9 Barkham N, Keen HI, Coates LC, et al. Clinical and imaging efficacy of infliximab in HLA-B27-positive patients with magnetic resonance imaging-determined early sacroiliitis. Arthritis Rheum 2009:60:946-54.

10 Braun J, Brandt J, Listing J, et al. Long-term efficacy and safety of infliximab in the treatment of ankylosing spondylitis: an open, observational, extension study of a three-month, randomized, placebo-controlled trial. Arthritis Rheum 2003:48:2224-33.

11 Catherine S, Oliver MF. Time to Diagnosis of Ankylosing Spondylitis in an Irish Cohort and the effect on work disability. [abstract]. Arthritis Rheum 2010;62(Suppl 10):555.

12 Pato E, Bañares A, Jover JA, et al. Undiagnosed spondyloarthropathy in patients presenting with anterior uveitis. J Rheumatol 2000;27:2198-202.

13 Fernández-Melón J, Muñoz-Fernández S, Hidalgo V, et al. Uveitis as the initial clinical manifestation in patients with spondyloarthropathies. I Rheumatol 2004:31:524-7. 